\title{
Substituição total do milho e parcial do feno do capim-tifton por palma forrageira em dietas para vacas em lactação. Produção, composição do leite e custos com alimentação ${ }^{1}$
}

\author{
Veronaldo Souza de Oliveira ${ }^{2}$, Marcelo de Andrade Ferreira ${ }^{3^{*}}$, Adriana Guim ${ }^{3}$, Elisa Cristina \\ Modesto $^{3}$, Bárbara Lucena Arnaud ${ }^{4}$, Fabiana Maria da Silva ${ }^{5}$ \\ ${ }^{1}$ Parte da tese de Doutorado do primeiro autor apresentada ao Programa de Doutorado Integrado em Zootecnia da UFRPE. Trabalho \\ financiado pelo CNPq. \\ 2 Programa de Pós-Graduação Integrado em Zootecnia da UFRPE - Recife-PE. \\ ${ }^{3}$ Departamento de Zootecnia/UFRPE. \\ 4 Zootecnista, MS. \\ ${ }^{5}$ Graduanda em Zootecnia. \\ * Bolsista do CNPq
}

RESUMO - O experimento foi conduzido com o objetivo de avaliar a influência de dietas com teores crescentes de palma forrageira sobre a produção, a composição do leite e o perfil dos ácidos graxos do leite de vacas holandesas em lactação. Os animais $(583 \pm 7,07 \mathrm{~kg})$ foram alimentados com dietas formuladas com diferentes níveis $(0 ; 12,0 ; 25,0 ; 38,0$ e $51,0 \%)$ de palma forrageira (Opuntia fícus indica Mill) em substituição total ao milho (Zea mays L.) e em substituição parcial ao feno de capimtifton (Cynodon spp). Foram utilizadas cinco vacas distribuídas em um quadrado latino 5 x 5 . Cada período experimental teve duração de 17 dias, dez para adaptação dos animais à dieta e sete para coleta de dados. A produção de leite, total (kg/dia) e corrigida para 3,5\% de gordura (kg/dia), o teor de gordura (\%) e a produção de gordura (kg/dia) do leite $(20,65 ; 19,76 ; 3,73$ e 0,745 , respectivamente) não foram influenciados pela introdução de palma nas dietas. O perfil de ácidos graxos da gordura do leite não foi influenciado (quanto aos ácidos cáprico, láurico, mirístico, linoléico, linolênico e araquídico) pelos níveis de palma na dieta, entretanto, houve aumento linear dos ácidos de cadeia intermediária (palmítico e palmitoléico) e tendência inversa para os ácidos esteárico e oléico. A inclusão de palma forrageira em substituição ao milho e parte do feno de capimtifton para vacas holandesas em lactação não influenciou a produção e a composição do leite, exceto a concentração dos ácidos graxos de cadeia longa, que apresentou comportamento linear decrescente.

Palavras-chave: glândula mamária, qualidade do leite, perfil de ácidos graxos

\section{Effects of replacing corn and Tifton hay with forage cactus on milk production and composition of lactating dairy cows}

\begin{abstract}
The objective of this trial was to evaluate the effect of replacing Tifton hay and corn with forage cactus (Opuntia ficus indicaMill) on milk production and composition and milk fatty acid profile in lactating Holstein cows. Animals averaged $583 \pm 7.07 \mathrm{~kg}$ of body weight in the beginning of the trial and were fed diets containing (\% of DM): 0, 12.0, 25.0, 38.0 or $51.0 \%$ of forage cactus. Five Holstein cows were randomly assigned to treatments in a $5 \times 5$ Latin square design. Each experimental period lasted 17 days with 10 days for diet adaptation and seven days for data and sample collection. Milk production, $3.5 \%$ fat corrected milk, and milk fat content and yield were not affected by increasing the levels of forage cactus in the diet and averaged $20.65 \mathrm{~kg} / \mathrm{d}, 19.76 \mathrm{~kg} / \mathrm{d}, 3.73 \%$ and $0.745 \mathrm{~kg} / \mathrm{d}$, respectively. Milk contents of capric, lauric, mirystic, linoleic, linolenic e arachydic acids were not changed when the levels of forage cactus were increased in the diet. However, milk contents of the medium-chain fatty acids palmytic and palmitoleic reduced linearly while the opposite was observed for the long-chain fatty acids estearic and oleic. Although milk production and composition were not affected by replacing corn and Tifton hay with forage cactus, significant changes were found in the milk profile of medium and long-chain fatty acids by increasing the proportion of forage cactus in the diet.
\end{abstract}

Key Words: fatty acids profile, mammary gland, milk quality

\section{Introdução}

A zona semi-árida nordestina, apesar de possuir solo em sua maioria com fertilidade natural média a alta, tem como principal fator limitante ao crescimento das forrageiras o acentuado déficit hídrico na maioria dos meses do ano, associado a um regime pluviométrico inconsistente, conduzindo a ocorrência cíclica de períodos de 
estiagens prolongadas. Nessas condições, ocorre marcante estacionalidade na produção forrageira, que se concentra em apenas 4 a 5 meses do ano. A produção animal nessa região está condicionada ao uso intensivo, durante a maior parte do ano, de volumosos produzidos e preservados durante a estação chuvosa e à aquisição de concentrados.

Mesmo com essas limitações, a pecuária do estado de Pernambuco possui o quarto maior rebanho bovino ordenhado do Nordeste, e o segundo maior produtor de leite (litro/vaca/dia) da região. Na última década, o rebanho foi reduzido em $15 \%$, mas a produção de leite cresceu na mesma proporção, como resultado de sua melhora genética e da evolução de suas condições de alimentação e manejo (Datamétrica, 2004).

É fundamental o direcionamento das linhas de pesquisa de instituições responsáveis por este setor no desenvolvimento de alternativas viáveis com baixo custo de produção e de aplicabilidade no campo. Entre as tecnologias desenvolvidas e aplicáveis à região semi-árida, destacam-se os processos de ensilagem e fenação e o plantio adensado da palma forrageira.

No Brasil, o milho é a principal fonte de energia utilizada para composição dos concentrados, porém, sofre grande variação de preço ao longo do ano, haja vista sua intensa utilização na alimentação humana e nas dietas de aves e suínos (Véras et al., 2005).

Na tentativa de evitar a competição por alimentos entre o homem e os animais, tem-se pesquisado com bastante frequiência a utilização de fontes alternativas de carboidratos, como os subprodutos da agroindústria (mandioca, canade-açúcar e plantas forrageiras bem adaptadas às condições edafoclimáticas da região semi-árida, como a palma forrageira).

Em várias pesquisas, comprovou-se a riqueza da palma em carboidratos e seu potencial para substituição a fontes energéticas e volumosos como as silagens de milho e sorgo. O uso de palma forrageira para o gado de leite é uma prática comum, no entanto, são freqüentes os distúrbios nos animais, como redução na ruminação e diarréia, principalmente em virtude de sua utilização em excesso ou com volumoso de má qualidade. Para a eficiente utilização da palma, é essencial o uso de volumoso de boa qualidade, tendo em vista os custos e o equilíbrio entre os carboidratos fibrosos e os não-fibrosos.

Segundo Ferreira (2005), a composição química da palma varia conforme a espécie, a idade, a época do ano e os tratos culturais, mas essa forrageira pode ser considerada um alimento rico em carboidratos, sobretudo carboidratos nãofibrosos. Além disso, essa forrageira apresenta altas produções de MS por unidades de área, apesar dos baixos teores de FDN e PB. Esse autor destacou ainda sua importância como reserva de água e seu alto teor de cinzas. Cavalcanti (2005) avaliou o desempenho de vacas holandesas em lactação alimentadas com dietas com diferentes níveis de palma $(0 ; 12,5 ; 25,0 ; 37,5$ e 50,0\%) em substituição ao feno do capim-tifton, na forma de mistura completa, e não observou diferença significativa no consumo de MS e no teor de gordura do leite, entretanto, as produções de leite total e corrigida para $3,5 \%$ de gordura por dia sofreram efeito quadrático.

A substituição parcial da silagem de sorgo por níveis crescentes de palma forrageira $(12,0 ; 24,0$ e 36,0\%) em dietas para vacas holandesas foi estudada por Wanderley et al. (2002), que não observaram alterações no consumo de MS e na produção de leite, porém, o teor de gordura do leite apresentou comportamento quadrático quando o nível de palma na dieta atingiu $25,1 \%$.

Com os objetivos de agregar valor ao leite e esclarecer os possíveis fatores para a redução do teor de gordura do leite, tem-se intensificado pesquisas na área de manipulação não apenas da composição em gordura e proteína, mas também quanto ao perfil de ácidos graxos da gordura do leite.

Os ácidos graxos constituem aproximadamente $90 \%$ dos triglicerídeos, que, por sua vez, compõem quase a totalidade dos lipídios do leite e dos tecidos adiposos dos animais. Assim, o perfil de ácidos graxos é determinante das propriedades físicas, químicas e organolépticas dos alimentos. Estudos recentes confirmaram que a maior parte da redução da gordura do leite (DGL) é produzida pelo isômero do ácido linoléico conjugado (CLA) $\mathrm{C}_{18: 2} \operatorname{trans} 10$, cis12, inibindo a ação das enzimas promotoras da lipogênese na glândula mamária (Medeiros, 2002).

Os compostos denominados CLA (ácido linoléicos conjugados) representam produtos que se formam como intermediários durante a biohidrogenação ruminal do ácido linoléico (cis9, cis12 $\left.\mathrm{C}_{18: 2}\right)$ a ácido esteárico $\left(\mathrm{C}_{18: 0}\right)$ por ação das bactérias. Apesar de mais de dez isômeros já terem sido identificados na gordura do leite, o CLA cis-9, trans-11, tem sido encontrado em maior concentração, de 75 a $80 \%$ do CLA total. A maior parte desse isômero é sintetizado endogenamente por ação da enzima delta 9 dessaturase presente na glândula mamária, tendo como substrato os ácidos graxos $\mathrm{C}_{18: 1}$ trans-11 e $\mathrm{C}_{18: 1}$ trans-7, formados durante o processo de biohidrogenação ruminal dos ácidos graxos poliinsaturados presentes na dieta (Griinari et al., 2000; Corl et al., 2000).

A biohidrogenação de ácidos graxos poliinsaturados no rúmen para 18:2 trans-10 cis-12 parece ser favorecida em alguns tipos específicos de dietas. Além da presença 
de gordura poliinsaturada, baixos valores de $\mathrm{pH}$ ruminal parecem ser determinantes para formação de isômeros de CLA com ligações duplas do tipo trans na posição 10 na cadeia de ácido graxo. Dietas com alto teor de concentrados, baixo teor de forragens, presença de forragens finamente picadas e adição de ionóforos têm resultado em valores mais elevados de C18:2trans-10, cis-12(Baumgard et al., 2000).

O objetivo neste experimento foi avaliar os efeitos da substituição do milho (total) e do feno do capim-tifton (parcial) por palma forrageira sobre a produção, a composição e o perfil dos ácidos graxos do leite de vacas holandesas.

\section{Material e Métodos}

O experimento foi conduzido na Estação Experimental de São Bento do Una, pertencente à Empresa Pernambucana de Pesquisa Agropecuária - IPA, no período de setembro a novembro de 2004. As temperaturas mais elevadas são observadas nos meses de novembro a janeiro, superiores a $30^{\circ} \mathrm{C}$. A temperatura média mensal varia de 21,7 a $25^{\circ} \mathrm{C}$ e a mínima, de 15,7 a $15,2^{\circ} \mathrm{C}$. A unidade relativa do ar é, em média, de 66\% (FIDEPE, 1982).

Foram utilizadas cinco vacas holandesas em lactação com peso vivo (PV) médio de $583 \pm 7,07 \mathrm{~kg}$ e período de lactação no início do experimento em torno de 110 dias. Os animais foram alojados em baias individuais com cerca de arame farpado e piso de terra batida, com área coberta de $6 \mathrm{~m}^{2}$, dotadas de cocho para fornecimento e controle do consumo de alimentos e bebedouro para fornecimento de água à vontade.

Os animais foram distribuídos em quadrado latino 5 x 5 , com cinco animais, cinco níveis de palma forrageira $(0,0$; 12,0; 25,0;38,0; e 51,0\% da MS da dieta) e cinco períodos experimentais de 17 dias (dez para adaptação dos animais às dietas e sete para coleta dos dados e das amostras). A dieta foi fornecida duas vezes ao dia, às 6 e 16h, na forma de ração completa, permitindo sobras de 5 a $10 \%$ do total da MS.

$\mathrm{Na}$ Tabela 1 consta a composição química dos ingredientes (com base na MS) e, na Tabela 2, a composição percentual das dietas experimentais.

Os tratamentos consistiram da inclusão de níveis crescentes de palma forrageira (Opuntia fícus indica Mill), em substituição ao milho e ao feno de tifton, Cynodon ssp., (Tabela 2). A dieta com $0 \%$ de palma foi formulada para atender às exigências de produção de vacas multíparas produzindo $20 \mathrm{~kg}$ de leite/dia com 3,5\% de gordura e, em média, aos 150 dias de lactação, segundo recomendações do NRC (2001). A palma forrageira e o feno de capim-tifton foram
Tabela 1 - Composição química dos ingredientes das dietas experimentais, com base na MS

Table 1 - Chemical composition of ingredients of the experimental diets, $\%$ of $D M$

\begin{tabular}{|c|c|c|c|c|}
\hline \multirow[t]{2}{*}{$\begin{array}{l}\text { Item } \\
\text { Item }\end{array}$} & \multicolumn{4}{|c|}{$\begin{array}{c}\text { Alimento } \\
\text { Feed }\end{array}$} \\
\hline & $\begin{array}{c}\text { Palma } \\
\text { Forage cactus }\end{array}$ & $\begin{array}{c}\text { Feno de } \\
\text { tifton } \\
\text { Tifton } \\
\text { hay }\end{array}$ & $\begin{array}{c}\text { Milho } \\
\text { moído } \\
\text { Cracked } \\
\text { corn }\end{array}$ & $\begin{array}{c}\text { Farelo de } \\
\text { soja } \\
\text { Soybean } \\
\text { meal }\end{array}$ \\
\hline $\operatorname{MS}(\%)(D M \%)$ & 9,43 & 90,72 & 88,33 & 89,12 \\
\hline $\mathrm{PB}^{1}(C P)$ & 4,2 & 9,74 & 9,05 & 51,45 \\
\hline $\mathrm{FDN}^{1}(N D F)$ & 35,81 & 77,61 & 15,61 & 15,30 \\
\hline $\mathrm{FDA}^{1}(A D F)$ & 26,03 & 39,85 & 8,46 & 12,57 \\
\hline $\mathrm{EE}^{1}(E E)$ & 1,36 & 2,17 & 4,36 & 2,19 \\
\hline $\mathrm{MM}^{1}(A s h)$ & 8,29 & 9,33 & 2,74 & 7,29 \\
\hline $\mathrm{CT}^{1}(T C)$ & 86,15 & 78,76 & 84,02 & 39,07 \\
\hline $\mathrm{CNF}^{1}(N F C)$ & 50,34 & 1,15 & 68,41 & 23,77 \\
\hline
\end{tabular}

$1 \% \mathrm{MS}(\% \mathrm{DM})$.

Tabela 2 - Composição percentual das dietas experimentais Table 2 - Ingredient composition of the experimental diets

\begin{tabular}{|c|c|c|c|c|c|}
\hline \multirow[b]{2}{*}{$\begin{array}{l}\text { Alimento } \\
\text { Feed }\end{array}$} & \multicolumn{5}{|c|}{$\begin{array}{l}\text { Nível de inclusão de palma (\%) } \\
\text { Forage cactus level }\end{array}$} \\
\hline & 0,0 & 12,0 & 25,0 & 38,0 & 51,0 \\
\hline Palma $^{1}$ & 0,00 & 12,00 & 25,00 & 38,00 & 51,00 \\
\hline $\begin{array}{l}\text { Forage cactus } \\
\text { Feno }^{1}\end{array}$ & 67,42 & 58,75 & 49,44 & 39,02 & 27,85 \\
\hline $\begin{array}{l}\text { Hay } \\
\text { Milho moído }\end{array}$ & 16,39 & 12,12 & 8,11 & 3,88 & 0,00 \\
\hline $\begin{array}{l}\text { Cracked corn } \\
\text { Farelo de soja } 1 \\
\text { Soybean meal }\end{array}$ & 14,19 & 15,13 & 15,45 & 17,0 & 19,15 \\
\hline $\begin{array}{l}\text { Mistura mineral } \\
\text { Mineral mix }\end{array}$ & 2,00 & 2,00 & 2,00 & 2,00 & 2,00 \\
\hline
\end{tabular}

$1 \%$ MS (\%DM).

passados em máquina forrageira para redução do tamanho das partículas para 8 a 5 e 4 a $2 \mathrm{~cm}$, respectivamente.

Durante o período de coleta, amostras dos alimentos fornecidos e das sobras foram recolhidas diariamente pela manhã, pré-secas em estufa de ventilação forçada e armazenadas para posterior processamento. Ao final do experimento, foi feita uma amostra composta por animal por período. Posteriormente, as amostras foram submetidas a análises da composição química, segundo metodologia descrita por Silva \& Queiroz (2002), para determinação dos teores de MS, cinzas, PB e EE. Para determinação dos teores de FDN e FDA, aplicaram-se as metodologias descritas por Van Soest et al. (1991). Para análise da FDN do concentrado e da palma forrageira, as amostras foram mergulhadas em solução de alfa-amilase e uréia a $8 \mathrm{M}$ e aquecidas até $90^{\circ} \mathrm{C}$ antes de serem submetidas à digestão no aparelho especi- 
fico, segundo Van Soest al. (1991). Todas amostras de FDN foram corrigidas para cinzas e proteína.

A composição em carboidratos totais (CT) foi estimada por meio da equação proposta por Sniffen et al. (1992), $\mathrm{CT}=100-(\% \mathrm{~PB}+\% \mathrm{EE}+\%$ cinzas $)$ e a dos carboidratos nãofibrosos (CNF), pela equação preconizada por Hall et al. (2001), em que CNF $=100 \%-(\mathrm{PB} \%+\mathrm{FDN} \%-\mathrm{FDNpb} \%+$ $\mathrm{EE} \%+$ Cinzas\%) e FDNpb = proteína bruta insolúvel em detergente neutro. Os nutrientes digestíveis totais (NDT) foram calculados pela equação: $\mathrm{NDT}=\mathrm{PBD}+\mathrm{CT}+2,25$ (EED), de acordo com Sniffen et al. (1992).

A composição química das dietas experimentais encontra-se descrita na Tabela 3.

As vacas foram ordenhadas duas vezes ao dia ( 5 e $15 \mathrm{~h}$ ). Foram coletadas amostras de leite, nas duas ordenhas, do $11 \underline{0}, 15 \underline{0}$ e $16^{\circ}$ dias de cada período experimental. A amostra coletada pela manhã foi mantida em refrigerador até a amostra da tarde ser coletada e resfriada para depois serem analisadas quanto aos teores de gordura (Pregnolatto \& Pregnolatto, 1985). Para análise, utilizou-se uma quantidade proporcional à produção de leite de cada ordenha. As amostras foram misturadas e uma alíquota de $11 \mathrm{~mL}$ de leite foi retirada, armazenada e colocada em butirômetro contendo $10 \mathrm{~mL}$ de ácido sulfúrico e $1 \mathrm{~mL}$ de álcool isoamílico.Após esse procedimento, os butirômetros foram mantidos em centrífuga por cinco minutos para posterior leitura de sua porcentagem de gordura. A produção leite foi corrigida para $3,5 \%$ de gordura (PLCG) pela equação descrita por Sklan et al. (1992): PLCG $=(0,432+0,1625$ x GL) x PL $(\mathrm{kg} / \mathrm{dia})$. No mesmo período, amostras de leite também foramcoletadas e armazenadas a $-18^{\circ} \mathrm{C}$ para posterior análise do perfil de ácidos graxos.

Tabela 3 - Composição química das dietas experimentais Table 3 - Chemical composition of the experimental diets

\begin{tabular}{|c|c|c|c|c|c|}
\hline \multirow[b]{2}{*}{$\begin{array}{l}\text { Nutriente } \\
\text { Nutrient }\end{array}$} & \multicolumn{5}{|c|}{$\begin{array}{c}\text { Nível de inclusão de palma (\%) } \\
\text { Forage cactus level }\end{array}$} \\
\hline & 0,0 & 12,0 & 25,0 & 38,0 & 51,0 \\
\hline MS $(\%)(D M)$ & 90,25 & 44,50 & 28,72 & 21,20 & 16,81 \\
\hline $\mathrm{MO}(O M)$ & 92,22 & 92,08 & 91,98 & 91,87 & 91,78 \\
\hline $\mathrm{PB}(C P)^{1}$ & 15,18 & 14,94 & 14,76 & 14,68 & 14,84 \\
\hline $\mathrm{EE}^{1}$ & 1,85 & 1,82 & 1,79 & 1,76 & 1,73 \\
\hline FDNcp $(N D F)^{1,2}$ & 57,51 & 54,23 & 50,69 & 47,14 & 43,13 \\
\hline FDA $(A D F)^{1}$ & 29,88 & 29,17 & 28,30 & 27,43 & 26,34 \\
\hline $\mathrm{CNF}(N F C)^{1,3}$ & 15,06 & 18,56 & 22,46 & 26,16 & 30,02 \\
\hline NDT (TDN) (\%) & 59,85 & 61,69 & 60,70 & 61,63 & 61,69 \\
\hline $\mathrm{CT}(T C)(\%)$ & 72,57 & 71,85 & 73,15 & 73,30 & 73,15 \\
\hline Cinzas $(A s h)^{1}$ & 7,78 & 7,92 & 8,20 & 8,13 & 8,22 \\
\hline
\end{tabular}

1 (\% na MS); ${ }^{2}$ fibra em detergente neutro corrigida para proteína e cinzas ${ }^{3} \mathrm{CNF} \mathrm{CP}=$ carboidratos não-fibrosos corrigidos para cinzas e proteína

${ }^{1}(\%$ of DM $) ;{ }^{2} \mathrm{NDFp}=$ neutral detergent fiber corrected for ash and protein; ${ }^{3} \mathrm{NFC}=$ non fiber carbohydrates corrected for ash and protein.
A extração de gordura das amostras do leite foi realizada no Laboratório de Nutrição Animal do Departamento de Zootecnia da Universidade Federal Rural de Pernambuco UFRPE, adotando-se a técnica descrita por Murphy et al. (1999), de congelamento-descongelamento e centrifugação. As amostras de leite foram descongeladas em temperatura ambiente, transferidas para tubos apropriados e centrifugadas $(18.000 \mathrm{G})$ por 10 minutos a $8^{\circ} \mathrm{C}$ até a separação da gordura (sobrenadante). Os ésteres metílicos dos ácidos graxos foram obtidos pela transesterificação dos triacilgliceróis, pelo método 5509 da ISO (1978), em solução de n-heptano e KOH/metanol. Após centrifugação do leite, a gordura (100 mg) foi transferida para tubo de ensaio com tampa rosqueável com capacidade de $10 \mathrm{~mL}$. O material foi adicionado de 2,0 $\mathrm{mL}$ de n-heptano e agitado até total solubilização. Em seguida, foram adicionados 2,0 mL de solução $2 \mathrm{~mol} / \mathrm{L}$ de $\mathrm{KOH}$ em metanol agitando-se vigorosamente a mistura por 5 minutos até a separação completa das fases. A fase superior (ésteres metílicos de ácidos graxos) foi pipetada e transferida para tubos de eppendorf identificados e armazenados a $-18^{\circ} \mathrm{C}$ até a determinação do perfil dos ácidos graxos.

O perfil dos ácidos graxos foi determinado no Laboratório de Cromatografia Instrumental (LCI) do Departamento de Engenharia Química da Universidade Federal de Pernambuco, pelo método de cromatografia gasosa, utilizando-se cromatográfo CG- Master, com coluna DB-WAX, $30 \mathrm{~m} \times 0,53 \mathrm{~mm} \times 1 \mu \mathrm{m}$. O fluxo de $\mathrm{H}_{2}$ (gás de arraste) e $\mathrm{N}_{2}$ foi de $30 \mathrm{~mL} / \mathrm{min}$ e $300 \mathrm{~mL} / \mathrm{min}$ para o ar sintético, com volume injetado de $1 \mu \mathrm{L}$. As temperaturas do detector e injetor foram de $210^{\circ} \mathrm{C}$. O perfil dos ácidos graxos foi expresso em porcentagem do total de ácidos graxos.

Os animais foram pesados no início do experimento e no início e final de cada semana de coleta de cada período experimental.

Os dados foram submetidos às análises de variância e regressão por meio do sistema de Análises Estatísticas e Genéticas SAEG (UFV, 1998). Os critérios utilizados para escolha do modelo foram a significância dos coeficientes de regressão, a 5\% de probabilidade, e o coeficiente dedeterminação $\left(\mathrm{r}^{2}\right)$, obtidos pela relação entre a soma de quadrados da regressão e a soma de quadrados de tratamentos e do fenômeno biológico.

\section{Resultados e Discussão}

Na Tabela 4 são apresentados os dados de produção média de leite e de leite corrigido para 3,5\% de gordura, os teores de gordura, a produção de gordura e os consumos de PB, EE e NDT. Não houve efeito da inclusão de palma na 
Tabela 4 - Produções de leite média (PRODL) e corrigida para 3,5\% gordura (PLCG), produção (PG) e teor (G) de gordura do leite, consumos de proteína bruta (CPB), extrato etéreo (CEE) e nutrientes digestíveis totais (CNDT) em vacas holandesas alimentadas com dietas formuladas com palma forrageira em substituição ao milho e ao feno de tifton

Table 4 - Milk production (MP), 3.5\% fat corrected milk (FCM), milk fat content (FC) and yield (FY), and intakes of CP (CPI), EE (EEI), and TDNI according to different levels of forage cactus in the diet

\begin{tabular}{|c|c|c|c|c|c|c|c|c|c|}
\hline & \multicolumn{5}{|c|}{$\begin{array}{l}\text { Nível de inclusão de palma (\%MS) } \\
\text { Forage cactus level }(\% D M)\end{array}$} & \multirow[t]{2}{*}{ CV (\%) } & \multirow[t]{2}{*}{ ER } & \multicolumn{2}{|c|}{$\mathrm{P}$} \\
\hline & 0,0 & 12,0 & 25,0 & 38,0 & 51,0 & & & $\mathrm{~L}$ & $\mathrm{Q}$ \\
\hline $\begin{array}{l}\operatorname{PRODL}(\mathrm{kg} / \mathrm{dia}) \\
M P(k g / \text { day })\end{array}$ & 20,34 & 20,20 & 21,78 & 20,58 & 20,35 & 5,50 & $\hat{\mathrm{y}}=20,65$ & NS & NS \\
\hline $\begin{array}{l}\text { PLCG (kg/dia) } \\
F C M(k g / \text { day })\end{array}$ & 19,85 & 20,10 & 20,57 & 18,97 & 19,31 & 6,30 & $\hat{\mathrm{y}}=19,76$ & NS & NS \\
\hline $\begin{array}{l}\text { TG }(\%) \\
F C(\%)\end{array}$ & 3,83 & 4,0 & 3,66 & 3,50 & 3,68 & 4,50 & $\hat{\mathrm{y}}=3,73$ & NS & NS \\
\hline $\begin{array}{l}\mathrm{PG}(\mathrm{kg} / \mathrm{dia}) \\
F Y, k g(\text { day })\end{array}$ & 0,763 & 0,760 & 0,774 & 0,717 & 0,713 & 7,50 & $\hat{\mathrm{y}}=0,745$ & NS & NS \\
\hline $\begin{array}{l}\text { CPB }(\mathrm{kg} / \mathrm{dia}) \\
\text { CPI, kg (day) }\end{array}$ & 3,27 & 3,30 & 3,06 & 2,80 & 2,53 & 9,67 & 1 & 0,0004 & NS \\
\hline $\begin{array}{l}\mathrm{CEE}(\mathrm{kg} / \mathrm{dia}) \\
\text { EEI (kg/day) }\end{array}$ & 0,38 & 0,39 & 0,36 & 0,33 & 0,29 & 9,17 & 2 & 0,001 & NS \\
\hline $\begin{array}{l}\text { CNDT (kg/dia) } \\
\text { TDNI (kg/day) }\end{array}$ & 12,52 & 13,81 & 12,24 & 11,46 & 10,11 & 11,93 & 3 & 0,0041 & NS \\
\hline
\end{tabular}

$\mathrm{NS}=$ não-significativo (not significant); $\mathrm{P}=$ palma (forage cactus); $\mathrm{p}=$ probabilidade (probability)

$\mathrm{L}=$ linear (linear); $\mathrm{Q}=$ quadrática (quadratic).

$1=\hat{y}=3,3892-0,0155 \mathrm{P}\left(\mathrm{r}^{2}=0,92\right) ; 2=\hat{\mathrm{y}}=0,4054-0,0020 \mathrm{P}\left(\mathrm{r}^{2}=0,90\right) ; 3=\hat{\mathrm{y}}=13,4609-0,0566 \mathrm{P}\left(\mathrm{r}^{2}=0,69\right)$.

dieta sobre as produções de leite total e corrigida para 3,5\% de gordura.

O comportamento regular da produção de leite pode ser explicado pelo equilíbrio energético-protéico mantido nas dietas; mesmo com a retirada gradual da fonte energética do milho, os carboidratos não-fibrosos oriundos da palma supriram essa necessidade. Esse equilíbrio pode ser comprovado pelo consumo médio de PB e NDT (Tabela 4), muito próximo aos valores estimados pelas equações do NRC (2001), que foram, respectivamente, 2,$65 ; 2,65 ; 2,76 ; 2,65$ e 2,64 kg/dia e 10,$78 ; 10,87 ; 11,05 ; 10,57$ e 10,66 kg/dia para CPB e CNDT.

Do mesmo modo, o teor e a produção de gordura total ( $\mathrm{kg} / \mathrm{dia})$ não foram influenciados pelos níveis de palma nas dietas e apresentaram percentual médio de $3,7 \%$ e $0,745 \mathrm{~kg}$, respectivamente.

O NRC (2001) recomenda que dietas para vacas em lactação sejam formuladas com mínimo de 25\% de FDN na MS total e que parte (19\%) dessa FDN seja proveniente de volumosos. Do mesmo modo, o valor mínimo de FDA deve ser de $21 \%$ da MS quando o valor máximo de CNF na MS for $44 \%$. Mesmo na dieta com maior percentual de palma (51\%), essas exigências mínimas em fibra efetiva de origem forrageira foram atendidas, o que, possivelmente, contribuiu para evitar a redução do teor de gordura do leite. Resultado semelhante foi relatado por Cavalcanti (2005), que, utilizando palma forrageira em níveis crescentes em substituição ao feno de tifton em dietas para vacas holandesas, também não observou alterações no teor de gordura do leite mantendo o mínimo recomendado de fibra na dieta.

Para inibição das enzimas lipogênicas e diminuição do teor de gordura do leite, segundo Griinari et al. (1998), duas condições são essenciais: dietas ricas em ácidos graxos insaturados ou modificação no ambiente ruminal (baixo $\mathrm{pH}$, baixo teor de fibra, dieta rica em concentrado). Tudo indica que as dietas experimentais favoreceram o ambiente ruminal e não interferiram na lipogênese, visto que o percentual de FDN nas dietas atendeu às exigências mínimas preconizadas pelo NRC (2001), mantendo a relação volumoso:concentrado de 70:30 a 80:20. O pH ruminal não foi determinado, mas resultados na literatura comprovam que, em dietas contendo palma, o $\mathrm{pH}$ tem se mantido entre 7,0 e 7,2 (Ben Salen et al., 1996).

Na Tabela 5 encontra-se a análise simplificada do comprometimento da receita com alimentação em relação à renda com a produção do leite. Foram considerados os preços (em kg, com base na MS) de referência do estado de Pernambuco quando o valor do dólar da época era $\mathrm{R} \$ 2,23$ : feno de capim-tifton $=\mathrm{R} \$ 0,30$; farelo de milho $=\mathrm{R} \$ 0,50$; farelo de soja $=\mathrm{R} \$ 0,80$; mistura mineral $=\mathrm{R} \$ 1,0$; palma forrageira $=\mathrm{R} \$ 0,20 . \mathrm{O}$ custo da MS foi determinado multi- 
Tabela 5 - Produção de leite, consumo de matéria seca (MS), custo da matéria seca $(\mathrm{kg})$, preço do leite, receita do leite, custos das dietas e comprometimento da receita com alimentação (CRA)

Table 5 - $\quad$ Milk production, DM intake (DMI), cost of DM/kg, milk price, milk income, diet costs, and proportion of the income spent with feeding (ICF)

\begin{tabular}{|c|c|c|c|c|c|}
\hline & \multicolumn{5}{|c|}{$\begin{array}{c}\text { Nível de inclusão de palma (\%MS) } \\
\text { Forage cactus level }(\% D M)\end{array}$} \\
\hline & 0,0 & 12,0 & 25,0 & 38,0 & 51,0 \\
\hline $\begin{array}{l}\text { Produção de leite }(\mathrm{kg} / \mathrm{dia}) \\
\text { Milk production }(\mathrm{kg} / \text { day })\end{array}$ & 20,34 & 20,20 & 21,78 & 20,58 & 20,35 \\
\hline $\begin{array}{l}\text { Consumo de MS (kg/dia) } \\
\text { DM intake (kg/day) }\end{array}$ & 20,93 & 21,87 & 20,17 & 18,60 & 16,48 \\
\hline Custo total MS (R\$) & 8,79 & 8,75 & 7,66 & 6,88 & 5,93 \\
\hline $\begin{array}{l}\text { Total DM cost } \\
\text { Preço do leite }(\mathrm{R} \$) \\
\text { Milk price }\end{array}$ & 0,50 & 0,50 & 0,50 & 0,50 & 0,50 \\
\hline $\begin{array}{l}\text { Receita do leite }(\mathrm{R} \$) \\
\text { Milk income }\end{array}$ & 10,17 & 10,10 & 10,89 & 10,29 & 10,17 \\
\hline Dieta $(\mathrm{R} \$) / \mathrm{kg} \mathrm{MS}$ & 0,42 & 0,40 & 0,38 & 0,37 & 0,36 \\
\hline $\begin{array}{l}\operatorname{Diet}(R \$)(k g D M) \\
\text { CRA }(\%) \\
I C F\end{array}$ & 86,0 & 87,0 & 70,0 & 67,0 & 58,0 \\
\hline
\end{tabular}

plicando-se os preços dos ingredientes pelos percentuais utilizados nas dietas (Tabela 2), o que possibilitou encontrar o preço final do quilograma da dieta, que foi multiplicado pelo consumo médio de MS (kg/dia) em cada tratamento.

Como pode ser observado na Tabela 5, o comprometimento da receita com alimentação na dieta com $0,0 \%$ de palma correspondeu a $86,0 \%$ da receita do leite, enquanto, no tratamento com $51,0 \%$ de palma, o comprometimento foi de $58,0 \%$. Considerando o elevado preço do milho e as dificuldades de sua produção na Região Nordeste, a palma forrageira pode constituir alternativa regional de fonte de energia, baixando os custos de produção sem alterar a produção de leite e o teor de gordura.

Os teores crescentes de palma nas dietas não influenciaram $(\mathrm{P}>0,05)$ as concentrações dos ácidos de cadeia curta $\mathrm{C}_{10: 0}$ (cáprico), $\mathrm{C}_{12: 0}$ (láurico) e $\mathrm{C}_{14: 0}$ (mirístico), que apresentaram valores médios de 1,$91 ; 3,40$ e 13,40\%. Os percentuais dos ácidos palmítico $\left(\mathrm{C}_{16: 0}\right)$ e palmitoléico $\left(\mathrm{C}_{16: 1}\right)$ aumentaram linearmente, com valores de 40,14 a 53,54 e de 2,06 a $3,41 \%$, respectivamente (Tabela 6).

A menor produção de ácidos graxos de cadeias curta e média $\left(\mathrm{C}_{6: 0}\right.$ a $\left.\mathrm{C}_{16: 0}\right)$ está associada à redução do teor de gordura do leite (Ávila et al., 2000; Piperova et al., 2000; Solomon et al., 2000). Como não houve variação nos percentuais de gordura do leite entre os tratamentos experimentais, esse comportamento no perfil dos ácidos graxos de cadeia curta era previsível.

Com a resposta uniforme dos percentuais dos ácidos de cadeia curta, provavelmente não houve inibição da síntese de novo dos ácidos graxos na glândula mamária, o que poderia explicar o comportamento linear crescente das concentrações dos ácidos de cadeia intermediária, visto que, segundo Chilliard et al. (2000), a origem dos ácidos graxos de cadeias curta e média é resultado da lipogênese da glândula mamária, por meio da síntese

Tabela 6 - Perfil de ácidos graxos do leite (\%), coeficientes de variação (CV), equações de regressão ajustadas (ER) e probabilidade $(p)$ referente aos efeitos linear $(L)$ e quadrático $(Q)$ dos níveis de inclusão de palma forrageira nas dietas

Table 6 - Milk fatty acids profile (\%), coefficients of variation (VC), adjusted regression equations (RE) and probability level (p) for linear (L) and quadratic $(Q)$ effects according to different levels of forage cactus in the diet

\begin{tabular}{|c|c|c|c|c|c|c|c|c|c|}
\hline \multirow[t]{2}{*}{$\begin{array}{l}\text { Ácido graxo } \\
\text { Fatty acid }\end{array}$} & \multicolumn{5}{|c|}{$\begin{array}{c}\text { Nível de inclusão de palma (\%MS) } \\
\text { Forage cactus level }(\% D M)\end{array}$} & \multirow[t]{2}{*}{$\mathrm{CV}(\%)$} & \multirow[t]{2}{*}{ ER } & \multicolumn{2}{|c|}{$\mathrm{P}$} \\
\hline & 0,0 & 12,0 & 25,0 & 38,0 & 51,0 & & & $\mathrm{~L}$ & Q \\
\hline $\mathrm{C}_{10: 0}$ & 1,98 & 1,63 & 2,12 & 1,85 & 1,99 & 42,34 & $\hat{y}=1,91$ & NS & NS \\
\hline $\mathrm{C}_{12: 0}$ & 3,30 & 2,92 & 3,90 & 3,61 & 3,26 & 20,84 & $\hat{y}=3,40$ & NS & NS \\
\hline $\mathrm{C}_{14: 0}$ & 14,00 & 11,83 & 14,35 & 13,37 & 13,46 & 10,65 & $\hat{\mathrm{y}}=13,40$ & NS & NS \\
\hline$C_{16: 0}$ & 40,14 & 49,56 & 44,53 & 47,25 & 53,54 & 11,0 & 1 & 0,0058 & NS \\
\hline $\mathrm{C}_{16}:_{1}$ & 2,06 & 1,86 & 2,44 & 2,87 & 3,41 & 31,99 & 2 & 0,0071 & NS \\
\hline $\mathrm{C}_{18: 0}$ & 13,65 & 11,93 & 9,18 & 8,12 & 6,25 & 29,25 & 3 & 0,0006 & NS \\
\hline $\mathrm{C}_{18}:{ }_{1}$ & 19,59 & 17,99 & 15,39 & 16,59 & 15,08 & 19,36 & 4 & 0,0444 & NS \\
\hline $\mathrm{C}_{18}: 2$ & 1,50 & 1,73 & 1,97 & 3,03 & 2,11 & 54,41 & $\hat{\mathrm{y}}=2,07$ & NS & NS \\
\hline $\mathrm{C}_{18: 3}$ & 0,97 & 0,86 & 0,85 & 0,98 & 0,67 & 26,92 & $\hat{\mathrm{y}}=0,86$ & NS & NS \\
\hline $\mathrm{C}_{20: 0}$ & 0,73 & 0,50 & 0,50 & 0,68 & 0,64 & 53,12 & $\hat{\mathrm{y}}=0,61$ & NS & NS \\
\hline
\end{tabular}

$\mathrm{NS}=$ não-significativo (not significant); $\mathrm{P}=$ palma (forage cactus); $\mathrm{p}=$ probabilidade (probability); $\mathrm{L}=$ linear (linear); $\mathrm{Q}=\mathrm{quadrática} \mathrm{(quadratic).}$

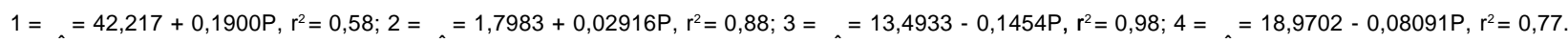


de novo, a partir de acetato e beta-hidroxibutirato. A redução linear no consumo e na digestibilidade da FDN poderia alterar a relação acetato:propionato, no entanto, como a proporção de volumoso das dietas foi superior, é possível que a fermentação acética tenha prevalecido. A presença de pectina na composição da palma forrageira também pode ter favorecido essa fermentação, refletindo positivamente na produção dos ácidos graxos de cadeia intermediária, sem, no entanto, interferir na produção de gordura do leite, pois, segundo Van Soest (1994), alimentos com alto teor de pectina têm efeito desejável em dietas para vacas leiteiras por manterem estável o $\mathrm{pH}$ ruminal e favorecerem a fermentação acética. A possibilidade de presençade pectina na composição química da palma forrageira $(23,3 \%)$ foi sugerida por Melo et al. (2003), contudo, outras pesquisas devem ser realizadas para validação e quantificação desse carboidrato nessa cactácea.

Os percentuais dos ácidos de cadeia longa esteárico $\left(\mathrm{C}_{18: 0}\right)$ e oléico $\left(\mathrm{C}_{18: 1}\right)$ sofreram redução significativa $(\mathrm{P}<0,05)$ com a adição de palma nas dietas. Mesmo que a composição dos ácidos graxos das dietas não tenha sido determinada, é possível que estes resultados tenham sidos influenciados pelo baixo aporte de fontes desses ácidos graxos com a retirada do milho e de parte do feno. Além da menor oferta desses ingredientes nas dietas, a diminuição linear no consumo de EE e MS (Tabelas 4 e 5) pode ter influenciado também a redução no perfil desses ácidos do leite, visto que a glândula mamária não é capaz de elongar a cadeia de $C_{16: 0}$ para $C_{18: 0}$ (Chilliard et al., 2000).

As concentrações dos demais ácidos de cadeia longa, $\mathrm{C}_{18: 2}$, (linoléico), $\mathrm{C}_{18: 3}$ (linolênico) e $\mathrm{C}_{20: 0}$ (araquidíco), não foram influenciadas pela inclusão de palma nas dietas e apresentaram médias de 2,07;0,86 e 0,61, respectivamente.

\section{Conclusões}

A inclusão de palma forrageira em substituição ao milho e parte do feno do capim-tifton na dieta de vacas holandesas em lactação não alterou a produção e o teor de gordura do leite, entretanto, influenciou negativamente o perfil dos ácidos graxos esteárico e oléico.

\section{Literatura Citada}

ÁVILA, C.D.; DePETERS, E.J.; PEREZ-MONTI, H. et al. Influences of saturation ratio of supplemental dietary fat on digestion and milk yield in dairy cows. Journal of Dairy Science, v.80, n.9, p.2204-2212, 2000.

BAUMGARD, L.H.; CORL, B.A.; DWYER, D.A. et al. Identification of the conjugated linoleic acid isomer that inhibits fat synthesis. Animal Journal Physiology Regulatory Integrative, v.278, p.179-184, 2000.
BEN SALEM, H.; NEFZAOUI, A., ABDOULI, H. et al. Effect of increasing level of spineless cactus (Opuntia ficus indica var. intermis) on intake and digestion by sheep given straw-based. Animal Science, v.62, p.293-299, 1996.

CAVALCANTI, C.V.A. Palma forrageira (Opuntia ficus indica Mill) e uréia em substituição ao feno de tifton (Cynodon spp) em dietas de vacas Holandesas em lactação. Recife. Universidade Federal Rural de Pernambuco, 2005. 57p. Dissertação (Mestrado em Zootecnia) - Universidade Federal Rural de Pernambuco, 2005.

CHILLIARD, Y.; FERLAY, A.; MANSBRIDGE, R.M. et al. Ruminant milk fat plasticity: nutritional control of satured, polyunsatured, trans and conjugated fatty acids. Annales de Zootechnia, v.49, p.181-205, 2000.

CORL, B.A.; BAUMGARD, L.H.; DWYER, D.A. et al. The role of delta-9-desaturated in the production of cis-9, trans-11 CLA and other delta- 9 desaturated fatty acids in milk fat. Journal of Dairy Science, v.83, p.164-171, 2000.

DATAMETRICA. Projeto palma. Recife: Federação da Agricultura do Estado de Pernambuco, 2004. 110p. (Relatório Técnico).

FERREIRA, M.A. Palma forrageira na alimentação de bovinos leiteiros. Recife: Universidade Federal Rural do Pernambuco, 2005. 68p.

FUNDAÇÃO DE INFORMAÇÕES PARA O DESENVOLVIMENTO DE PERNAMBUCO - FIDEPE. Monografias municipais. São Bento do Una; Recife, 1982. 80p.

GRIINARI, J.M.; DWYER, D.A.; MCGUIRE, M.A. et al. Transoctadecenoic acids and milk fat depression in lactating dairy cows. Journal of Dairy Science, v.81, n.5, p.1251- 1261, 1998.

GRIINARI, J.M.; CORI, B.; LACY, S. et al. Conjugated linoleic acid is synthesized endogenously in lactating dairy cows by delta- 9 desaturase. Journal of Nutrition, v.130, p.2285-2291, 2000.

HALL, M.B. Recentes avanços em carboidratos não-fibrosos na nutrição de vacas leiteiras. In: SIMPÓSIO INTERNACIONAL DE BOVINOCULTURA DE LEITE: Novos conceitos em nutrição, 2., 2001, Lavras. Anais... Lavras: Universidade Federal de Lavras, 2001. p.149-159.

INTERNATIONAL ORGANIZATION FOR STANDARDIZATION - ISO. Animal and vegetable fats and oils - Preparation of methyl esters of fatty acids. Geneve, 1978. p.1-6. (Method ISO 5509).

MELO, A.A.S.; FERREIRA, M.A.; VÉRAS, A.S.C. et al. Substituição parcial do farelo de soja por uréia e palma forrageira em dietas para vacas em lactação. Digestibilidade. Acta Scientiarum. Animal Sciences, v.25, n.2, p.339-345, 2003

MEDEIROS, S.R. Ácido linoléico conjugado: teores nos alimentos e seu uso no aumento da produção de leite com maior teor de proteína e perfil de ácidos graxos modificado. Piracicaba: Escola Superior de Agricultura "Luiz de Queiroz", Universidade de São Paulo, 2002. 97p. Tese (Doutorado em Agronomia - Ciência Animal e Pastagens) Universidade de São Paulo, 2002.

MURPHY, J.J.; CONNOLLY, J.F.; McNEILL, G.P. Effects on milk fat composition and cow performance of feeding concentrates containing full fat rapessed and maize distillers grains on grass-silage based diets.Livestock Production Science, v.44, p.1-11, 1999.

NATIONAL RESEARCH COUNCIL - NRC. Nutrient requirement of the dairy cattle. 7.ed. Washigton: D.C., 2001. 381p.

PIPEROVA, L.S.; TETER, B.B.; BRUCKENTAL, I. et al. Mammary lipogenic enzyme activity, trans fatty acids and conjugated linoleic acids are altered in lactating dairy cows fed a milk fat-depressing diet. Journal of Nutrition, v.30, p.2568-2574, 2000.

PREGNOLATTO, W.; PREGNOLATTO, N.P. Normas analíticas do Instituto Adolfo Lutz - métodos químicos e físicos para análise de alimentos. 3.ed. São Paulo: Impressa Oficial do Estado, v.1, 1985. 533p. 
SILVA, D.J.; QUEIROZ, A.C. Análise de alimentos (métodos químicos e biológicos). 3.ed. Viçosa, MG: Editora UFV, 2002. $235 \mathrm{p}$.

SNIFFEN, C.J.; O'CONNOR, J.D.; Van SOEST, P.S. A net carbohydrate and protein availability. Journal of Animal Science, v.70, n.11, p.3562-3577, 1992.

SKLAN, D.; ASHKENAZI, R.; BRAUN, A. et al. Fatty acids, cacium soaps of fatty acids and cottonseeds fed to high yielding cows. Journal of Dairy Science, v.75, n.9, p.2463-2472, 1992.

SOLOMON, R.; CHASE, L.E.; BEN-GHEDALIA, D. et al. The effect of nonstructural carbohydrate and addition of full fat extruded soybeans on the concentration of conjugated linoleic acid in the milk fat of dairy cows. Journal of Dairy Science, v.83, n.6, p.1322-1329, 2000.

UNIVERSIDADE FEDERAL DE VIÇOSA - UFV. SAEG - Sistema de análise estatística e genética. versão 8.0. Viçosa, MG: 1998. 150p. (Manual do usuário).

Van SOEST, P.J.; ROBERTSON, J.B.; LEWIS, B.A. Methods for extraction fiber, neutral detergent fiber and mostarch polysaccarides in relation to animal nutrition cows. Journal of Dairy Science, v.83, n.10, p.3583-3597, 1991.
Van SOEST, P.J. Nutritional ecology of the ruminant. 2.ed. New York: Cornell University Press, 1994. 476p.

VÉRAS, R.M.L.; FERREIRA, M.A.; ARAÚJO, C.V. et al. Substituição do milho por farelo de palma forrageira em dietas de ovinos em crescimento. Revista Brasileira de Zootecnia, v.34, n.1, p.294-256, 2005.

WANDERLEY, W.L.; FERREIRA, M.A.; ANDRADE, D.K.B. et al. Palma forrageira (Opuntia fícus idica Mill) em substituição à silagem de sorgo (Sorghum bicolor (L.) Moench) na alimentação de vacas leiteiras. Revista Brasileira de Zootecnia, v.31, n.1, p.273-281, 2002.

Recebido: 27/04/06 Aprovado: 18/12/06 